\title{
Study of the influence factors on the synthesis of Fe-MCM-48 with binary mixed cationic and anionic surfactants
}

\author{
Wei Zhao ${ }^{\text {b,* }}$, Lingdong Kong ${ }^{\text {a }}$, Yunfei Luo ${ }^{\text {a }}$, Quanzhi Li ${ }^{\text {a,* }}$ \\ ${ }^{a}$ Department of Chemistry, Key Laboratory of Molecular Catalysis and Innovative Materials, Fudan University, Shanghai 200433, PR China \\ ${ }^{\mathrm{b}}$ Research Center for Eco-Environmental Sciences, Chinese Academy of Sciences, Beijing 100085, PR China
}

Received 17 April 2006; received in revised form 12 October 2006; accepted 12 October 2006

Available online 27 November 2006

\begin{abstract}
Highly ordered Fe-MCM-48 was synthesized by a mixed template method under low molar ratio (0.17:1) of mixed surfactants to silica. The effect of various factors, such as Fe sources, the amount of Fe salt, $\mathrm{Si}$ sources, surfactant $/ \mathrm{SiO}_{2}$, crystallization temperature and crystallization time on the synthesis were discussed in detail. The Debye-Huckel theory, the theory of salts formation, the local effective surfactant packing parameter theory and the charge balance theory were used to explain the reason that various factors can affect the product structure reasonably. The optimum synthesis conditions for Fe-MCM-48 were obtained.
\end{abstract}

(C) 2006 Elsevier Inc. All rights reserved.

Keywords: Fe-MCM-48; Hydrothermal synthesis; Mixed surfactants; Crystallization; Mesoporous materials

\section{Introduction}

In the beginning of the 1990 s, a new family of ordered M41S mesoporous silica was discovered and immediately received great attention because of its uniform channels, high surface area and good thermal stability [1]. Among this M41S family, MCM-48 with three-dimension channel system has several advantages over MCM-41 with onedimension channel system when they were applied to the adsorption and catalytic reaction. However, the formation of MCM-48 required very special synthesis conditions and large amount of surfactant if the cationic surfactant was used as the sole template [2]. In order to resolve this problem, we developed a new pathway to synthesize $\mathrm{Si}$, Al-MCM-48 with the binary mixed cationic-anionic surfactants method [3]. This method enabled the synthesis of MCM-48 easily under the low molar ratio of surfactant to silica $\left(\mathrm{Surf} / \mathrm{SiO}_{2}\right)$ and low surfactant concentration. And we further extended this method to synthesize the

\footnotetext{
* Corresponding authors.

E-mail addresses: zhaowei@rcees.ac.cn (W. Zhao), qzli@fudan.edu.cn (Q. Li).
}

Fe-MCM-48 with good catalytic performance on the phenol hydroxylation [4]. Meanwhile, the proofs that $\mathrm{Fe}^{3+}$ ion had been introduced into the MCM-48 framework were set up by the XRD, ${ }^{29}$ Si MASNMR, ESR and UVvisible results. However, the function of different synthesis factors only referred a few in these reports. In the present paper, we systemically studied the effects of Fe source, Si source, $\mathrm{Fe}$ salt amount, surfactant $/ \mathrm{SiO}_{2}$ and other hydrothermal conditions on the product structure and the optimum synthesis conditions for Fe-MCM-48 were obtained. Especially, the reason that various factors could affect the product structure was discussed in detail. We believe this work not only can help us to recognize the synthesis chemistry of Fe-MCM-48 deeply but also is useful to synthesize other high quality mesoporous silica containing transition metals.

\section{Experimental}

\subsection{Synthesis}

The synthesis mixture of Fe-MCM-48 was prepared as follows: Si source and $\mathrm{Fe}$ source were added to the mixture 
solution of cetyltrimethylammonium bromide $\left(\mathrm{C}_{16} \mathrm{H}_{33^{-}}\right.$ $\mathrm{Me}_{3} \mathrm{NBr}$, CTAB, imported from Denmark), sodium laurate $\left(\mathrm{C}_{11} \mathrm{H}_{23} \mathrm{COONa}\right.$, SL, First Chemical Co., Shanghai), $\mathrm{NaOH}$ (First Chemical Co., Shanghai) and $\mathrm{H}_{2} \mathrm{O}$. If there is not any special notice in this paper, the molar composition of the above mixture was $1.0 \quad \mathrm{SiO}_{2}: 0.153$ CTAB:0.017 SL:0.25 $\mathrm{Na}_{2} \mathrm{O}: 0.002-0.003 \quad \mathrm{Fe}_{2} \mathrm{O}_{3}: 100 \quad \mathrm{H}_{2} \mathrm{O}$. This solution was stirred at $30^{\circ} \mathrm{C}$ for $1 \mathrm{~h}$. After that, the mixture was placed in a static autoclave at $100{ }^{\circ} \mathrm{C}$ for four days. The solid product was recovered and calcined at $550{ }^{\circ} \mathrm{C}$ in air $\left(5^{\circ} \mathrm{C} / \mathrm{min}\right)$ for $4 \mathrm{~h}$. The Si sources included tetraethylorthosilicate (TEOS, First Chemical Co., Shanghai), water glass (Jiangpu Chemical Co., Shanghai) and fumed silica (Electrochemical Co., Shanghai). The $\mathrm{Fe}$ sources were $\mathrm{Fe}_{2}\left(\mathrm{SO}_{4}\right)_{3} \cdot x \mathrm{H}_{2} \mathrm{O}$ (the content of $\mathrm{Fe}$ is $22 \mathrm{wt} \%$, First Chemical Co., Shanghai), $\mathrm{FeCl}_{3} \cdot 6 \mathrm{H}_{2} \mathrm{O}$ (First Chemical Co., Shanghai), and $\mathrm{Fe}(\mathrm{NO})_{3} \cdot 9 \mathrm{H}_{2} \mathrm{O}$ (First Chemical Co., Shanghai), respectively.

\subsection{Characterization}

The powder X-ray diffraction patterns were recorded on the Rigaku D/Max-II A diffractometer (Ni-filtered $\mathrm{Cu}-\mathrm{K} \alpha$ radiation with $\lambda=1.542 \AA$ ) operated at $40 \mathrm{kV}$ and $20 \mathrm{~mA}$. The TEM images were obtained on the JEM-2010 Transmission Electron Microscope operated at $200 \mathrm{kV}$. The SEM images were obtained on the Philips XL-30 Scan Electron Microscope.

\section{Results and discussion}

\subsection{The XRD, TEM and SEM image of Fe-MCM-48 sample}

Fig. 1 is the XRD pattern of Fe-MCM-48 sample synthesized using $\mathrm{Fe}_{2}\left(\mathrm{SO}_{4}\right)_{3} \cdot x \mathrm{H}_{2} \mathrm{O}$ and TEOS as Fe source and $\mathrm{Si}$ source, respectively. It corresponds well to those reported for purely siliceous MCM-48 [1]. Fig. 2 is the TEM image of this sample. The order arrangement of lattice dot along [1 10$]$ direction means the sample has excellent textural uniformity. The SEM image (Fig. 3) of this sample suggests that the sample is composed of sphere particles and there is no other structure phase. All of these results show that the sample is high quality Fe-MCM-48 material.

\subsection{The effect of Fe sources}

The effect of different $\mathrm{Fe}$ sources, such as $\mathrm{Fe}_{2}\left(\mathrm{SO}_{4}\right)_{3}$. $x \mathrm{H}_{2} \mathrm{O}, \mathrm{FeCl}_{3} \cdot 6 \mathrm{H}_{2} \mathrm{O}$ and $\mathrm{Fe}(\mathrm{NO})_{3} \cdot 9 \mathrm{H}_{2} \mathrm{O}$ on the product structure was studied under the condition that TEOS was used as the constant Si source. From Fig. 4, one can see that the XRD patterns of the two samples synthesized by $\mathrm{Fe}(\mathrm{NO})_{3} \cdot 9 \mathrm{H}_{2} \mathrm{O}$ and $\mathrm{FeCl}_{3} \cdot 6 \mathrm{H}_{2} \mathrm{O}$ are similar. Besides the main peak at $2.6^{\circ}$, there also exist two peaks at $2.2^{\circ}$ and $5.1^{\circ}$, respectively (Fig. 4, left b and c). Because

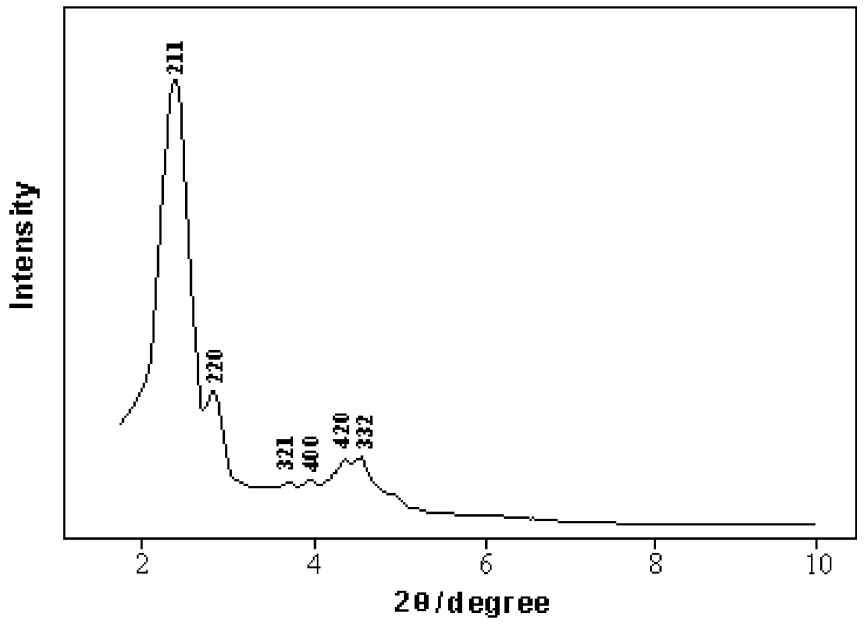

Fig. 1. XRD pattern of Fe-MCM-48 sample.

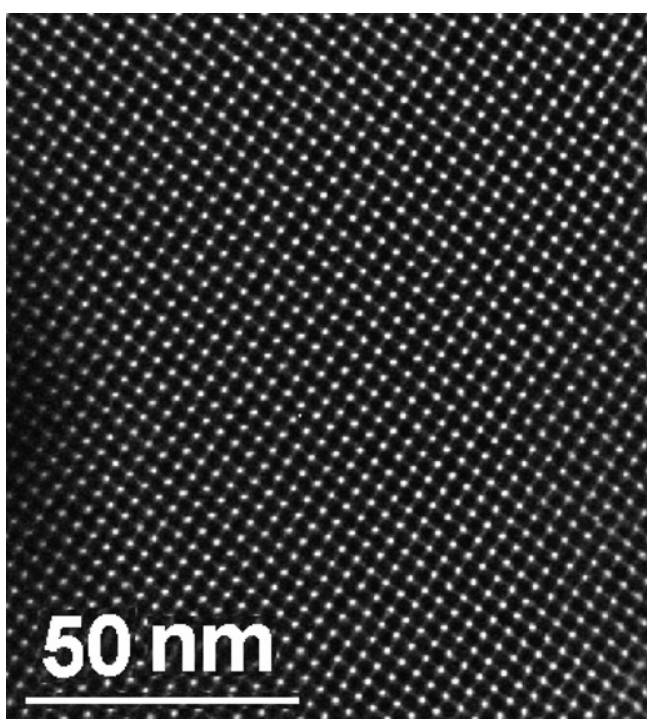

Fig. 2. TEM image of Fe-MCM-48 on the (110) cubic plane.

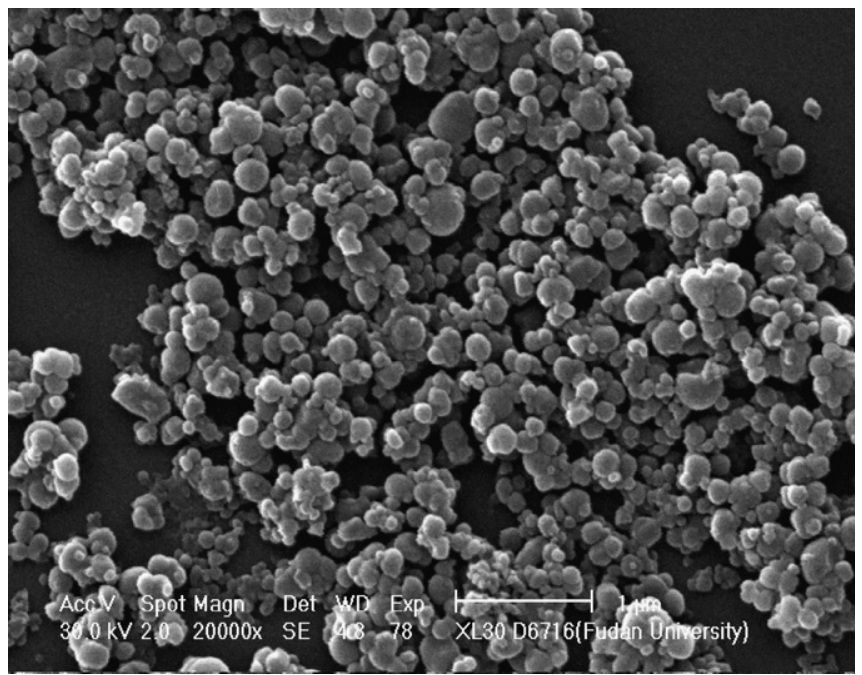

Fig. 3. SEM image of Fe-MCM-48 sample. 
the value of $5.1^{\circ}$ is almost two times larger than that of $2.6^{\circ}$. It means the product contains the lamella MCM-50 [5]. However, the appearing of peak at $2.2^{\circ}$ makes the two XRD patterns look like the cubic Pm3n structure [6]. After the two samples were calcined, both the $2.2^{\circ}$ peaks and $5.2^{\circ}$ peaks are disappearing in their XRD patterns, instead the characteristic diffraction peaks belonging to the cubic MCM-48 structure were exhibited solely. So, we can conclude that these two as-synthesis samples are the mixture of lamella phase MCM-50 and cubic phase MCM-48. Because the lamella phase is not stable, its structure will be destroyed during the calcinations (Fig. 4, right $\mathrm{b}$ and c). When $\mathrm{Fe}_{2}\left(\mathrm{SO}_{4}\right)_{3} \cdot x \mathrm{H}_{2} \mathrm{O}$ was used as Fe source, the pure phase MCM-48 with well resolved (211), (220), (420), (332) diffraction line can be obtained (Fig. 4a).

In this mixed surfactant system, we know the cationic surfactant (CTAB) is the main surfactant while the anionic surfactant (SL) is just an auxiliary one (The molar ratio of $\mathrm{CTAB} / \mathrm{SL}$ is 9). Thus, the assemble force of inorganic $\mathrm{Si}$ source with the organic mixed micelles mainly comes from the electrostatic interactions. After adding $\mathrm{Fe}$ salt, the anionic part of Fe salt will enter into the synthesis solution as the counter-ions for the cationic ammonium. According to the Debye-Huckel theory [7], the diffusion double electric layer thickness $1 / \kappa \quad\left(\kappa=\left(2 n_{0} Z^{2} e^{2} / \varepsilon K T\right)^{1 / 2}, n_{0}\right.$ : counter-ions concentration, $Z$ : counter-ions valence state, $e$ : electron charge, $\varepsilon$ : dielectric constant of media, $k$ : Boltzmann constant, $T$ : temperature) of organic-inorganic interface will become thinner with the addition of electrolyte. And more, the thickness of diffusion double electric layer will decrease more sharply when the anti-ions have the larger radius and higher valence state. From this point of view, the $\mathrm{SO}_{4}^{2-}$ is the most effective one to decrease the thickness of double electric layer among the three anions described above. Thus, $\mathrm{SO}_{4}^{2-}$ is more beneficial to the assemble procedure between the cationic ammonium and the inorganic silicate anions. In addition, compared to $\mathrm{NO}_{3}^{-}$and $\mathrm{Cl}^{-}$, the most hydrophobic $\mathrm{SO}_{4}^{2-}$ possesses the strongest affinity with the polar head of surfactant. Thus, $\mathrm{SO}_{4}^{2-}$ would replace to $\mathrm{Br}^{-}$and form a bi-surfactant specie in the form of $(\mathrm{CTA})_{2} \mathrm{SO}_{4}$. This (CTA $)_{2} \mathrm{SO}_{4}$ bi-surfactant species can decrease the repulsive force among the cationic ammonium effectively. As a result, the polar head area $a_{0}$ of cationic ammonium will decrease and the local effective surfactant packing parameter " $g$ " value [8] $\left(g=V / A_{0} l\right.$, where $V$ is the local volume of the surfactant chains plus any cosolvent organic molecules between the chains, $A_{0}$ is the effective head group area at the micelle surface, and $l$ is the kinetic surfactant tail length or curvature elastic energy) needed for the formation of cubic phase $\mathrm{Fe}$ MCM-48 will be easy to get. Certainly, since the existence of SL, the procedure that the anionic part of $\mathrm{Fe}$ salt replaces the counter-ion in the quaternary surfactant probably can't be conduced totally. Thus, a fraction of Fe salt anions can be localized and play some different roles in another molecular zone (or stage) of sol-gel synthesis system. In short, compared to $\mathrm{SO}_{4}^{2-}, \mathrm{NO}_{3}^{-}$and $\mathrm{Cl}^{-}$are not beneficial to obtain the pure phase Fe-MCM-48 due to their weaker hydrophobic, mono-surfactant species $\left(\mathrm{CTA} / \mathrm{Br} / \mathrm{Cl} / \mathrm{NO}_{3}\right)$, smaller anti-ions radius and lower valence state.

\subsection{Effect of Si source}

The effect of different $\mathrm{Si}$ sources on the product structure was observed under the condition that $\mathrm{Fe}_{2}\left(\mathrm{SO}_{4}\right)_{3}$ was the constant Fe source. From Fig. 5, one can see that when TEOS and water glass are used as $\mathrm{Si}$ source, the cubic Fe-MCM-48 can be obtained and the degree of order on mesoscopic scales of the product synthesized with TEOS is better than that of the product synthesized with water glass. The lamella structural MCM-50 is obtained only when fumed silica is used as $\mathrm{Si}$ source (see Fig. 5c). Just as we know, for the above three $\mathrm{Si}$ sources, the sequence of condensation rate is as follows: water glass $>$ TEOS $>$ fumed silica. Based on this, we think that the formation of Fe-MCM-48 is closely related to the condensation rate of various $\mathrm{Si}$ species and the condensation rate must be neither too quick nor too slow under our synthetic system. This result also can be explained by the view of thermodynamic formula [9]:

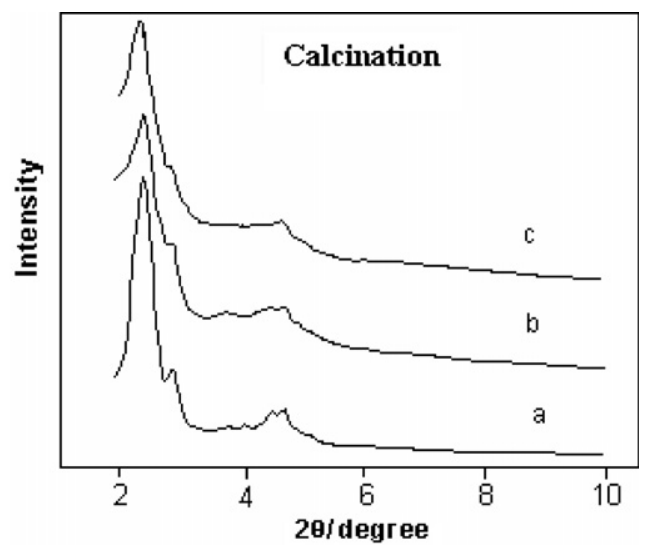

Fig. 4. The influence of Fe source on the product (a) $\mathrm{Fe}_{2}\left(\mathrm{SO}_{4}\right)_{3} \cdot x \mathrm{H}_{2} \mathrm{O}$, (b) $\mathrm{Fe}\left(\mathrm{NO}_{3}\right)_{3} \cdot 9 \mathrm{H}_{2} \mathrm{O}$ and (c) $\mathrm{FeCl}_{3} \cdot 6 \mathrm{H}_{2} \mathrm{O}$. 

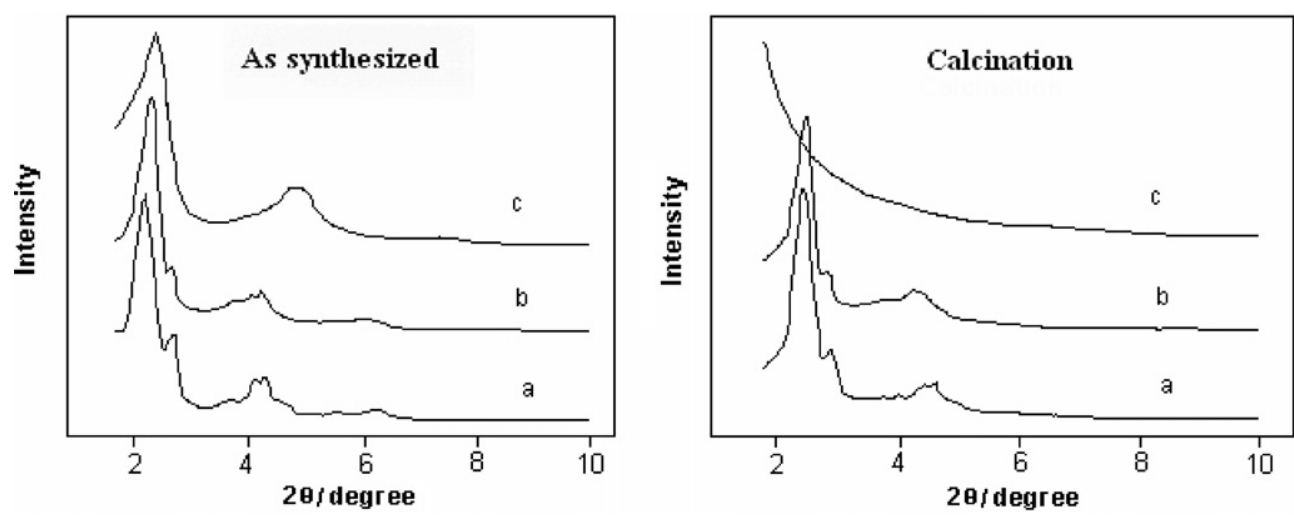

Fig. 5. The influence of Si source on the product (a) TEOS, (b) water glass and (c) fumed silica.

$(\delta G / \delta A)_{A=A_{0}}=0$

$G(A, \rho)=G_{\text {intra }}(A)+G_{\text {wall }}(\rho)+G_{\text {inter }}(A, \rho)+G_{\text {sol }}$

When other synthesis conditions keep constant, $G_{\text {wall }}$ and $G_{\text {inter }}(A, \rho)$ will be the more important free energy than $G_{\text {intra }}$ and $G_{\text {sol }}$ for the synthesis system if we only observe the effect of different $\mathrm{Si}$ sources on the product structure. So the Eq. (2) can be simplified to: $G(A, \rho)=G_{\text {wall }}(\rho)+$ $G_{\text {inter }}(A, \rho)$. When $(\delta G / \delta A)_{A=A_{0}}=0, A_{0}$ will only be related to the charge density of silica-polymer $(\rho)$. In fact, every synthetic system always has an optimum value of the head area $\left(A_{0}\right)$ under the different synthetic conditions and the different $A_{0}$ will be corresponded to the different structure. When the fumed silica is used as Si source, the interaction among inorganic $\mathrm{Si}$ species is weak because the condensation rate of its $\mathrm{Si}$ species is slow. As a result, the polymer silicate anions with high charge density will be advantageous to form and the value of $A_{0}$ will decrease [10]. Thus, the product is the lamellar structural MCM-50. In the case of TEOS, the condensation rate of its $\mathrm{Si}$ species is relatively faster. And more, this rate will cause the $A$ value of this system near to the $A_{0}$ value needed for the formation of MCM-48 with double continue gyroid structure (Ia3d). For Water glass, the condensation rate of its Si species also is advantageous to the formation of the cubic Ia3d structure. However, since the condensation rate of its $\mathrm{Si}$ species is very fast, the formation of the silica-wall will be too rapid to be in good order. So, the XRD pattern of its product will be worse than that of the product synthesized by TEOS

\subsection{Effect of the Fe salt amount}

The effect of Fe salt amount was observed under the condition that $\mathrm{Fe}_{2}\left(\mathrm{SO}_{4}\right)_{3}$ and TEOS were used as Fe source and $\mathrm{Si}$ source, respectively. The results are shown in Fig. 6 and Table 1. Fig. 6 (left) shows that the XRD pattern of sample " $d$ " is similar to the cubic octopolymer-like structure [11] or contain the lamellar MCM-50 phase. After calcination, the diffraction peaks of cubic octopolymer structure disappear but the diffraction peaks of cubic MCM-48 appear along (see Fig. 6 right d). It means the as-synthesized sample "d" should be the mixture of MCM-48 and MCM-50. From Table 1, we can also see that the phase transition from MCM-41 to MCM-48 then to MCM-50 occurs following the increase of the Fe salt amount. And more, this transition process is very sensitive to the variation of the Fe salt amount. The pure phase MCM-48 just form in a very narrow $\mathrm{Si} / \mathrm{Fe}$ ratio from 0.0048 to 0.006 . In our synthetic system, the cationic surfactant is the main template while the added Fe salt amount is very little compared to it (the molar ratio of
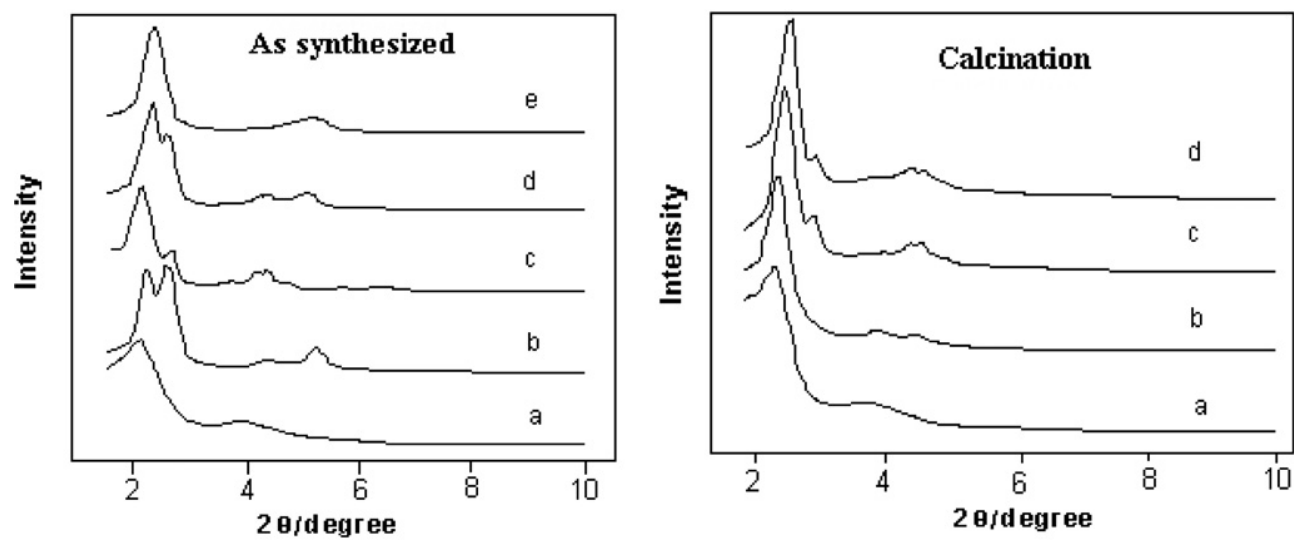

Fig. 6. The influence of iron sulfate amount on the product. (The sample mark is the same as that in Table 1.) 
Table 1

The effect of iron sulfate amount on the synthesis of Fe-MCM-48

\begin{tabular}{|c|c|c|c|c|c|c|c|}
\hline \multirow[t]{2}{*}{ Sample mark } & \multicolumn{6}{|c|}{ Gel molar composition } & \multirow[t]{2}{*}{ As synthesized sample } \\
\hline & $\mathrm{SiO}_{2}$ & СТАВ & $\mathrm{SL}$ & $\mathrm{Fe}_{2} \mathrm{O}_{3}$ & $\mathrm{Na}_{2} \mathrm{O}$ & $\mathrm{H}_{2} \mathrm{O}$ & \\
\hline $\mathrm{a}$ & 1 & 0.153 & 0.017 & 0.0018 & 0.25 & 100 & Fe-MCM-41 \\
\hline $\mathrm{b}$ & 1 & 0.153 & 0.017 & 0.0024 & 0.25 & 100 & Fe-MCM-41 \\
\hline $\mathrm{c}$ & 1 & 0.153 & 0.017 & 0.003 & 0.25 & 100 & Fe-MCM-48 \\
\hline d & 1 & 0.153 & 0.017 & 0.0036 & 0.25 & 100 & Fe-MCM-48 + Fe-MCM-50 \\
\hline $\mathrm{e}$ & 1 & 0.153 & 0.017 & 0.0042 & 0.25 & 100 & Fe-MCM-50 \\
\hline
\end{tabular}

$\mathrm{CTAB} / \mathrm{Fe}$ is 26). Thus, the effect of Fe salt amount can be seen as the effect of its $\mathrm{SO}_{4}^{2-}$ anions. It is well known that the interface between anionic inorganic Si species and cationic organic surfactant can be seen as the Helmholtz double electric layer. If the electron cloud density of cationic Helmholtz's layer is not equal to that of the anionic Helmholtz layer, it will bring about the distortion of interface and the formation of curvature. For example, if the added $\mathrm{SO}_{4}^{2-}$ amount is few, the electron cloud density of Helmholtz layer contained anionic silicate will be less than that of Helmholtz layer contained cationic $\mathrm{CTA}^{+}$due to the polymerization of silicate even there exist additional $\mathrm{SO}_{4}^{2-}$ ions. In this case, the interface would be convex and it is beneficial to form the hexagonal MCM-41 [12]. However, if the added $\mathrm{SO}_{4}^{2-}$ amount is enough, the electron cloud density of anionic Helmholtz layer can equal to that of cationic Helmholtz layer. In this case, the lamellar MCM-50 will be formed. If the added $\mathrm{SO}_{4}^{2-}$ amounts are just between the amounts described above, the gyroid face of cubic MCM-48 will form at the interface.

\subsection{Effect of synthetic temperature}

Fig. 7 shows that when the synthesized temperature was elevated from $80^{\circ} \mathrm{C}$ to $170{ }^{\circ} \mathrm{C}$, the phase transition is as follows:

Hexagonal phase $\left(80^{\circ} \mathrm{C}\right)$,

Cubic phase $\left(100^{\circ} \mathrm{C}\right)$,

Lamella phase $\left(120-140{ }^{\circ} \mathrm{C}\right)$,

Amorphous $\left(170^{\circ} \mathrm{C}\right)$.

We know micelles will gradually expand with the raise of temperature. So $g$ value will increase corresponding to the increase of " $V$ ". As a result, the product structures will change from hexagonal phase to cubic phase and then to lamellar phase.

In addition, the elevating temperature can promote the decomposition of the silica-polymer and make the charge density of silicate species increase [13]. According to the principle of charge balance, the charge density on the micelle interfaces should equal to that of the silica-polymers when the system energy is the most optimum [14], i.e.:

$\rho_{\varepsilon}=N / A$

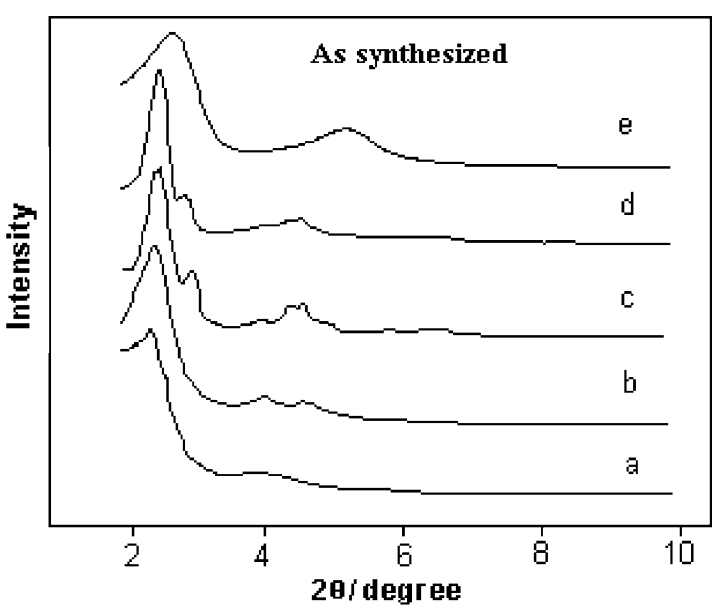

Fig. 7. The influence of synthesized temperature on the product (a) $80^{\circ} \mathrm{C}$, (b) $100{ }^{\circ} \mathrm{C}$, (c) $120^{\circ} \mathrm{C}$, (d) $140{ }^{\circ} \mathrm{C}$ and (e) $170{ }^{\circ} \mathrm{C}$.

( $\rho_{\varepsilon}:$ charge density on silica-polymer, $N$ : net charge on micelles interface, $A$ : interface area of micelle). To differentiate formula (3) and then transpose, we can obtain:

$\mathrm{d} A / \mathrm{d} \rho_{\varepsilon}=-N / \rho_{\varepsilon}^{2}<0$

This formula shows that the different polymer degree (or charge density) of silicate can change the interface area of micelle and then influence the product structure. When $\rho_{\varepsilon}$ increases, the micelle area will decrease, the shape of interface will change from high curvature to low curvature. For instance, the interface shape can change from cylinder through gyroid to flat, corresponding to the structure change from hexagonal MCM-41 through cubic MCM-48 to lamella MCM-50. However, if the synthetic temperature is too high $\left(170^{\circ} \mathrm{C}\right)$, the silica-polymer will de-polymerize completely. Finally, even the lamella phase also disappears.

\subsection{Effect of synthetic time}

Seen from Fig. 8, it is found that the XRD diffraction peaks of $2.6^{\circ}, 3.8^{\circ}$, and $7.5^{\circ}$ are observed for the sample that synthesized only one day. Among the three peaks, $3.8^{\circ}$ and $7.5^{\circ}$ are the diffraction peaks belonging to the surfactant while $2.6^{\circ}$ is related to an uncertain mesophase (Fig. 8a). After synthesizing two days, the peaks intensity of surfactant decreases obviously; on the contrary the peak intensity of uncertain mesophase increase evidently 

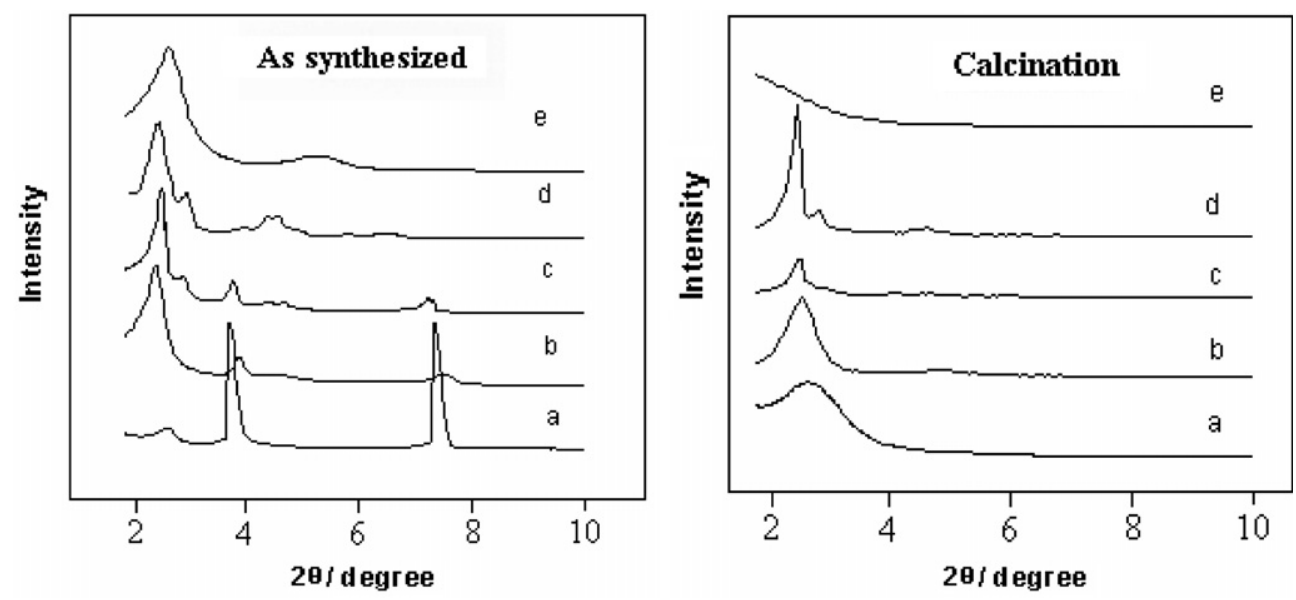

Fig. 8. The influence of synthesized time on the product (a) $24 \mathrm{~h}$, (b) $48 \mathrm{~h}$, (c) $72 \mathrm{~h}$, (d) $96 \mathrm{~h}$ and (e) $120 \mathrm{~h}$.

(Fig. 8b). For the third day, cubic phase MCM-48 (Fig. 8c) appears but its order degree on mesoscopic scales is somewhat worse than that of the fourth day's sample (Fig. 8d). At last, the lamella structure MCM-50 is unique product for the fifth day's sample. Since the TEOS was added directly to the mixture of surfactant and $\mathrm{NaOH}$ solution but did not hydrolyze in the $\mathrm{NaOH}$ solution previously, the hydrolysis of TEOS and the diffusion of silicate from inorganic phase to the interface need time. For the first synthesis day, only part of the uncertain mesophase is formed due to the weak cooperation between the silicate and surfactant and lots of free surfactant molecules exist in the solution. So the diffraction peaks of surfactant can be observed for this sample. After two days synthesis, more and more silicate would cooperate with surfactant. As a result, the amount of uncertain mesophase increases (Fig. 8b) but the number of free surfactant molecules decreases. With the prolonging of synthesis time, the silicates lied in the pore-wall of uncertain mesophase will further condensate and cause the change of interface curvature. Then, the uncertain mesophase will transfer to cubic MCM-48. If the synthesis time was prolonged to five days, the $\mathrm{pH}$ of the system will elevates because $\mathrm{Na}^{+}$ions released by the condensation of silicate increase. While the high $\mathrm{pH}$ is beneficial to form the thermodynamic more stable lamella phase [15].

\subsection{Effect of $\mathrm{CTAB} / \mathrm{SiO}_{2}$}

The effect of $\mathrm{CTAB} / \mathrm{SiO}_{2}$ on the product structure was shown in Fig. 9. It is found that the hexagonal phase product is appearing (Fig. 9a) when the ratio of $\mathrm{CTAB} / \mathrm{SiO}_{2}$ is 0.036 . With the ratio of $\mathrm{CTAB} / \mathrm{SiO}_{2}$ increases, the highly ordered MCM-41 (Fig. 9b) and MCM-48 (Fig. 9c) are produced and the corresponding ratios of $\mathrm{CTAB} / \mathrm{SiO}_{2}$ are 0.072 and 0.15 , respectively. If the ratio of $\mathrm{CTAB} / \mathrm{SiO}_{2}$ is 0.306 , the XRD diffraction intensity of this sample (Fig. 9d) is weaker than that of the sample synthesized by the ratio of $\mathrm{CTAB} / \mathrm{SiO}_{2}=0.15$ although its XRD dif-

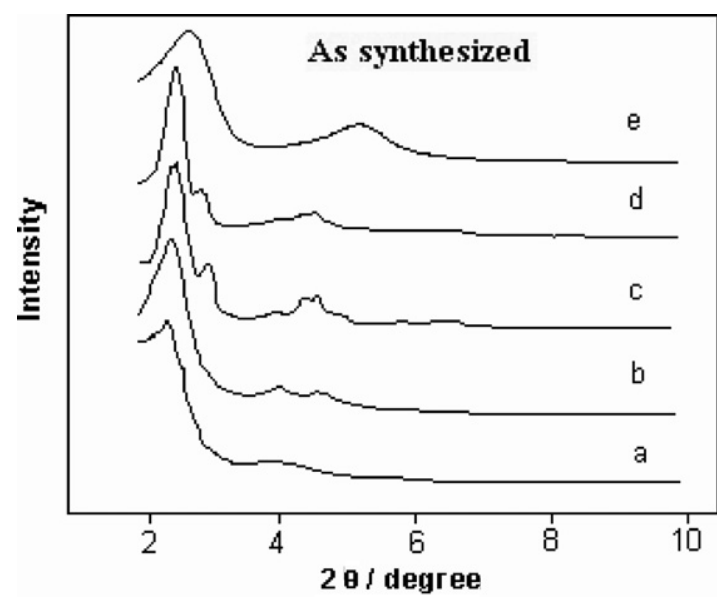

Fig. 9. The influence of $\mathrm{CTAB} / \mathrm{SiO}_{2}$ ratio on the product (a) $\mathrm{CTAB} /$ $\mathrm{SiO}_{2}=0.036$, (b) $\mathrm{CTAB} / \mathrm{SiO}_{2}=0.072$, (c) $\mathrm{CTAB} / \mathrm{SiO}_{2}=0.15$, (d) CTAB/ $\mathrm{SiO}_{2}=0.306$ and (e) $\mathrm{CTAB} / \mathrm{SiO}_{2}=0.612$.

fraction pattern is still cubic MCM-48. It suggests the cubic phase structure begins to degrade and will transform to lamella phase at this time. When the ratio of $\mathrm{CTAB} / \mathrm{SiO}_{2}$ increases to 0.612 , the XRD pattern (Fig. 9e) has transformed to the MCM-50 completely. According to the principle of charge balance, the negative charge density of silica-wall will increase following the increase of $\mathrm{CTA}^{+}$ when other synthetic conditions are constant. Then the effective pole head area $A_{0}$ of micelles will decrease while $\mathrm{g}$ value will increase. So the phase transition that transform from hexagonal phase to cubic phase then to lamella occurs with the increase of $\mathrm{CTAB} / \mathrm{SiO}_{2}$.

\section{Conclusion}

1. The effect of Fe source and Fe salt amount on the synthesis of Fe-MCM-48 can be ascribed to their inorganic anionic part when the cationic surfactant is used as the main template. Compared to $\mathrm{NO}_{3}^{-}$and $\mathrm{Cl}^{-}, \mathrm{SO}_{4}^{2}$ is more 
favorable to the synthesis of Fe-MCM-48. The formation of Fe-MCM-48 is very sensitive to the $\mathrm{Fe}$ salt amount in this system.

2. The effect of different $\mathrm{Si}$ sources on the synthesis of FeMCM-48 can be attributed to theirs condensation rate. The condensation rate should be neither too quick nor too slow.

3. The synthesis temperature can cause the change of the micelles volume " $V$ " and the de-polymerization rate of silica species. With the synthesis temperature increasing, mesophase will transform from hexagonal MCM-41 through cubic MCM-48 to lamellar phase MCM-50.

4. The ratio of $\mathrm{CTAB} / \mathrm{SiO}_{2}$ can influence the effective pole head area $A_{0}$ of the micelles. With the increasing ratio of $\mathrm{CTAB} / \mathrm{SiO}_{2}$, the phase transition from $\mathrm{MCM}-41$ to MCM-48 then to MCM-50 occurs.

5. The optimum synthetic conditions of Fe-MCM-48 under the low molar ratio $(0.17: 1)$ of mixed surfactants to silica are as follows:

$\mathrm{Fe}_{2}\left(\mathrm{SO}_{4}\right)_{3}$ and TEOS are used as $\mathrm{Fe}$ source and $\mathrm{Si}$ source, respectively. The molar composition of synthetic mixture is $1.0 \mathrm{SiO}_{2}: 0.002-0.003 \mathrm{Fe}_{2} \mathrm{O}_{3}: 0.153 \mathrm{CTAB}: 0.017$ SL:0.5 NaOH:100 $\mathrm{H}_{2} \mathrm{O}$. The hydrothermal condition is that crystallize at $100{ }^{\circ} \mathrm{C}$ for four days.

\section{Acknowledgments}

This work is supported by the projects of the National Basic Research Program of China (2004CB719504) and the China Natural Science Foundation (20303005).

\section{References}

[1] C.T. Kresge, M.E. Leonowicz, W.J. Roth, J.C. Vartuli, J.S. Beck, Nature 359 (1992) 710.

[2] A. Firouzi, D. Kumar, L.M. Bull, T. Besier, Q. Huo, G.D. Stucky, B.F. Chmelka, Science 267 (1995) 1138.

[3] F.X. Chen, L.M. Huang, Q.Z. Li, Chem. Mater. 9 (1997) 2685.

[4] W. Zhao, Y.F. Luo, P. Deng, Q.Z. Li, Catal. Lett. 73 (2001) 199.

[5] J.S. Beck, J.C. Vartuli, W.J. Roth, M.E. Leonowicz, C.T. Kresge, K.D. Schmitt, C.T.-W. Chu, D.H. Olson, E.W. Sheppard, S.B. McCullen, J.B. Higgins, J.L. Schlenkert, J. Am. Chem. Soc. 114 (1992) 10834.

[6] Q. Huo, D.I. Margolese, U. Ciesla, D.G. Demuth, P. Feng, T.E. Gier, P. Sieger, A. Firouzi, B.F. Chmelka, F. Schuth, G.D. Stuck, Chem. Mater. 6 (1994) 1176.

[7] R. Hogg, T.W. Healy, D.W. Fuerstenau, Trans. Faraday Soc. 62 (1966) 1638.

[8] G.D. Stucky, Q. Huo, A. Firouzi, B.F. Chmelka, Stud. Surf. Sci. Catal. 105 (1997) 3.

[9] A. Monnier, F. Schuth, Q. Huo, G.D. Stuck, A. Firous, Science 263 (1993) 1299.

[10] J. Marra, J. Phys. Chem. 90 (1986) 2145.

[11] J.C. Vartuli, K.D. Schmitt, C.T. Kresge, E.W. Sheppard, Stud. Surf. Sci. Catal. 84 (1994) 53.

[12] B. Echchahed, M. Morin, S. Blais, L. Bonnecviot, Micropor. Mesopor. Mater. 44-45 (2001) 53.

[13] S.D. Kinrade, T.W. Swaddle, Inorg. Chem. 27 (1988) 4253.

[14] L. Zhang, J. Qiao, H. Ding, G. Zhao, Acta Phys. Chim. Sinica 9 (1993) 478.

[15] R. Ryoo, J.M. Kim, J. Chem. Soc., Chem. Commun. (1995) 711. 